\title{
Bayesian spatio-temporal approach to identifying fish nurseries by validating persistence areas
}

\author{
Iosu Paradinas ${ }^{1, *}$, David Conesa ${ }^{1}$, M. Grazia Pennino ${ }^{2}$, Facundo Muñoz ${ }^{3}$, \\ Angel M. Fernández ${ }^{4}$, Antonio López-Quílez ${ }^{1}$, José María Bellido ${ }^{4}$ \\ ${ }^{1}$ Departament d'Estadística i Investigació Operativa, Universitat de València, C/ Dr. Moliner 50, Burjassot, 46100 Valencia, Spain \\ ${ }^{2}$ Institut de Recherche pour le Développement (IRD), UMR EME 212 (IRD/Ifremer/Université Montpellier 2), \\ Centre de Recherche Halieutique Méditerranéenne et Tropicale, Avenue Jean Monnet, B.P. 171, 34203 Sète cedex, France \\ ${ }^{3}$ Institut National de la Recherche Agronomique (INRA) - Centre Val de Loire Unité Amélioration, \\ Génétique et Physiologie Forestières, 2163 Avenue de la Pomme de Pin, CS 40001 ARDON, 45075 Orleans Cedex 2, France \\ ${ }^{4}$ Instituto Español de Oceanografía, Centro Oceanográfico de Murcia, C/ Varadero 1, San Pedro del Pinatar, 30740 Murcia, Spain
}

\begin{abstract}
Spatial and temporal closures of fish nursery areas to fishing have recently been recognized as useful tools for efficient fisheries management, as they preserve the reproductive potential of populations and increase the recruitment of target species. In order to identify and locate potential nursery areas for spatio-temporal closures, a solid understanding of speciesenvironment relationships is needed, as well as spatial identification of fish nurseries through the application of robust analyses. One way to achieve knowledge of fish nurseries is to analyse the persistence of recruitment hotspots. In this study, we propose the comparison of different spatiotemporal model structures to assess the persistence of a spatial process. In particular, we apply our approach to a 2-stage Bayesian hierarchical spatio-temporal model that describes both the occurrence and the abundance of European hake Merluccius merluccius recruits in the western Mediterranean Sea. Results clearly show areas of high occurrence and abundance, mainly along the shelf break and the upper slope of the Spanish Mediterranean coast. Understanding the distributional patterns associated with key life stages such as recruitment is essential for appropriate spatial management, including the implementation of Fisheries Restricted Areas and/or Marine Protected Areas that improve the management of fishery resources.
\end{abstract}

KEY WORDS: Nursery areas · Distribution pattern - Ecosystem approach - Spatial fisheries management $\cdot$ Spatio temporal analysis $\cdot$ Bayesian hierarchical modelling $\cdot$ Merluccius merluccius

Resale or republication not permitted without written consent of the publisher

\section{INTRODUCTION}

The study of species distribution is of great interest to fisheries science and marine ecology. Models that describe the spatial distribution of populations and its links with environmental features have been long debated (Planque et al. 2011). Understanding the spatial pattern of the distribution of recruits has been the subject of many scientific articles because this is a critical stage for fish stocks, and therefore reducing the fishing effort of unselective gears in recruitment areas will help avoid recruitment overfishing (Caddy et al. 2000). One of the fundamental objectives of an Ecosystem Approach to Fisheries Management (EAFM) framework is to ensure the long-term sustainability of the fishery by protecting key life cycle habitats such as spawning, breeding, or recruitment areas. Within this framework, a recommended management tool is the establishment of a network of Fisheries Restricted Areas (FRA) in regions where target species are known to aggregate in critical phases of their life cycle (e.g. recruits and/or juveniles) (Garofalo et al. 2011). 
The definition of a nursery ground has been a matter of debate during the last decade (Beck et al. 2001, Dahlgren et al. 2006). These definitions generally rely on direct measurements of the movement of juveniles from nursery habitats to the adult population (Beck et al. 2001, Gillanders et al. 2003). Unfortunately, direct measurements are not feasible for deep-water species, whose nursery grounds tend to be located in deeper waters as well. European hake Merluccius merluccius is one such species, whose recruits tend to inhabit the continental shelf and the upper slope (Orsi-Relini et al. 1989, Recasens et al. 1998, Maynou et al. 2003). As a result, Colloca et al. (2009) suggested using the persistence of abundance hotspots over time to identify nursery areas by means of Bayesian kriging and geostatistical aggregation curves.

Geostatistical methods in fisheries have been constrained to a spectrum of relatively simple models due to the restricted capabilities of the available packages in the frequentist statistical approach, and the expensive computational costs of Markov Chain Monte Carlo methods (Blangiardo et al. 2013) in the Bayesian counterpart. This becomes even more relevant when the interest is focused on spatio-temporal geostatistical modelling, the main reason being the higher level of complexity of such models. The Integrated Nested Laplace Approximation (INLA; Rue et al. 2009) avoids such computational issues by means of a user-friendly R package (Rue et al. 2013) that provides accurate numerical approximations to the posterior distributions of the parameters involved in the model.

Our objective in this study is twofold. First, we present a refinement of the methodology proposed by Colloca et al. (2009) to identify nursery areas. We assess the persistence of the spatial pattern by comparing alternative Bayesian hierarchical spatiotemporal models rather than by applying aggregation curves to the predictive posterior distributions. Moreover, we apply this approach using a 2-stage model (Maravelias 1999) in which we model both the presence/absence and the abundance conditional to presence. This not only allows us to identify high occurrence areas but also to highlight abundance hotspots in the same spatial scale. Each model allows us to incorporate different spatial, temporal or spatiotemporal effects along with information about environmental and geographical factors, the latter 2 as covariates. The inferential process for both models provides information about the final structure of our data; in other words, it shows the best model that adapts to our data, allowing us to differentiate whether there is a unique spatial process, or instead if the spatial structure varies over time. The prediction process (also known as Bayesian kriging; Diggle \& Ribeiro 2007) in which we predict the occurrence and the abundance in unsampled areas enables us to identify recruitment hotspots and possible nursery areas.

Our second aim is to estimate the distribution of hake nursery grounds on the Iberian Mediterranean coast. European hake is among the most important commercial species in the Mediterranean Sea, suffering from high fishing pressure (Lleonart 2005). In fact, in many Mediterranean countries there is still a considerable illegal market in small hake (Bellido et al. 2014). As a result, the juvenile fraction is particularly vulnerable, especially to the trawl fishery after the bottom settlement stage, when they aggregate over nursery grounds. A good understanding of the distributional patterns of this important life stage is essential for an appropriate EAFM (FAO 2008). A wide range of methodologies has been used to characterise hake nursery grounds in the Mediterranean (Abella et al. 2008, Colloca et al. 2009), but none have been applied to the Iberian coast, nor have environmental, geographical and temporal data been included in the models.

\section{MATERIALS AND METHODS}

Data on hake recruits were collected during the EU-funded MEDIterranean Trawl Survey (MEDITS) (Bertrand et al. 2002) project, carried out from spring to early summer (April to June) between 2000 and 2012. The MEDITS project used a stratified sampling design based on depth (5 bathymetric strata: 10 to 50, 51 to 100,101 to 200,201 to 500 and 501 to $700 \mathrm{~m}$ ) and geographical sub-area (GSA). Sampling stations were placed randomly within each bathymetric stratum at the beginning of the project. Sampling was performed in similar geographical locations in all subsequent years. This study concerns the trawlable grounds of GSA 06, which bordered the northern Iberian Mediterranean coast. Around 80 hauls divided into the 5 bathymetric strata were performed every year in this zone, comprising 1048 hauls in total. Only hake recruits were considered, defined as those individuals $<15 \mathrm{~cm}$ in total length (Bartolino et al. 2008, Druon et al. 2015).

Total weight of recruits $(\mathrm{kg})$ per 30 min of trawling was used as the catch per unit effort (CPUE) unit. A hake recruit presence/absence variable was created for each haul, with presence being CPUE values $>0$ and absence, CPUE equal to 0. Fig. 1 shows a map of 


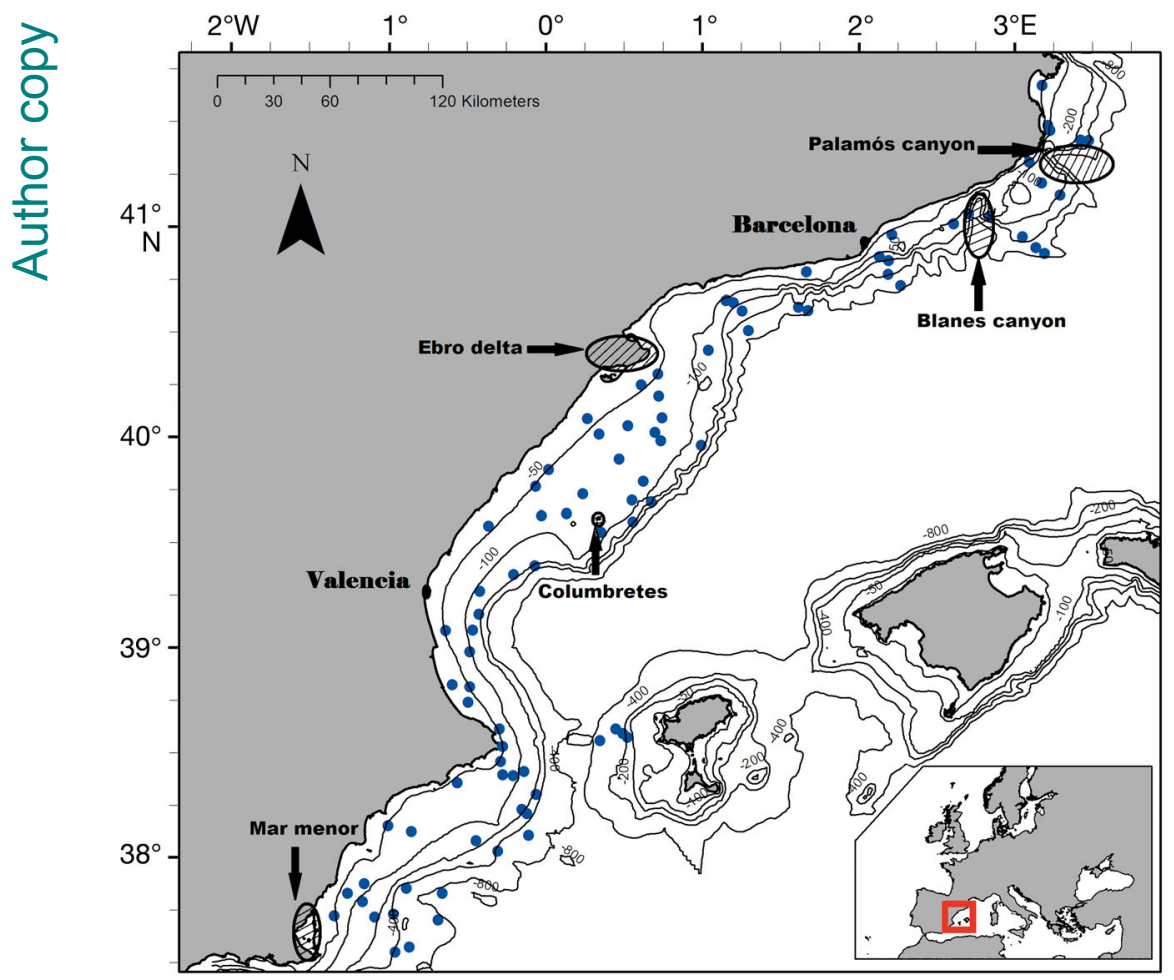

Fig. 1. Study area and expected distribution of the samples each year. Bathymetric contours are shown up to the $800 \mathrm{~m}$ depth strata according to the MEDIterranean Trawl Survey (MEDITS) sampling range

observed data and model parameters as random variables (Banerjee et al. 2003). They also allow the spatial component to be incorporated as a random-effect term in a natural way, thereby reducing its influence on estimates of the effects of geographical variables (Gelfand et al. 2006). Specifically, by treating the spatial effect as a variable of interest, Bayesian hierarchical spatial models can suggest the identity of additional covariates that may improve model fit, or the existence of area effects that may affect recruit density.

This study implements Bayesian hierarchical spatial models by using the INLA methodology (Rue et al. 2009) and software (see www.r-inla. org for more information). INLA provides accurate numerical approximations to the posterior marginal distributions of a large class of hierarchical models known as latent Gaussian Markov Random Field (GMRF) models (Rue \& Held 2004). Even for complex models, the clever exploitation of

the study area and the approximate locations sampled every year.

As mentioned previously, bathymetry is a very important explanatory variable in the distribution of hake (Orsi-Relini et al. 1989, Recasens et al. 1998, Maynou et al. 2003), but we also included the type of substratum, the sea surface temperature and the chl a concentration as potentially relevant environmental variables. Bathymetry and substratum maps were obtained as shapefiles from the IEO geoportal, accessible through the website of the Spanish Institute of Oceanography (www.ieo.es). Yearly and monthly sea surface temperature and chl a concentration maps were downloaded from the Giovanni online data system (http://disc.sci.gsfc.nasa. gov/giovanni) (Acker \& Leptoukh 2007).

\section{Bayesian framework}

Bayesian methods have several advantages over traditional methods of analysis and are increasingly used in fisheries research (Colloca et al. 2009, Muñoz et al. 2013, Pennino et al. 2014). Bayesian methods provide a more realistic and accurate estimation of uncertainty because they allow the use of both the the Markov property makes the computations remarkably fast.

In particular, for geostatistical problems where inference and prediction are relevant continuously in space, INLA implements the stochastic partial differential equations (SPDE) approach (Lindgren et al. 2011). This involves the approximation of a continuously indexed Gaussian Field (GF) with Matérn covariance function by a GMRF, which fits well into the INLA framework.

\section{Modelling nursery areas}

Point-referenced spatial models (Cressie 1993) are highly suitable for situations where observations are made within a defined continuous spatial domain. The final aim of these models is to predict quantities of interest at unsampled locations based on information gathered at sampled locations. However, accuracy is not always easy to achieve because there is often a large amount of variability surrounding the measurement of variables, and traditional prediction methods do not account for an attribute with more than one level of uncertainty. This variability leads to uncertain predictions, and consequently to unin- 
formed decision making. This can be avoided using the Bayesian framework. Point-referenced spatial models can be seen as Bayesian hierarchical models (Banerjee et al. 2003), in which (as mentioned above) it is conceptually easy to incorporate parameter uncertainty into the prediction process while including covariates, temporal effects and different likelihoods.

At each location, we had different information about the qualitative and quantitative spatial distribution of recruits: presence/absence and abundance at those places where they were present. As a result, we propose the use of different Bayesian hierarchical spatio-temporal models for each situation. While the presence/absence model provides an idea of the relative occurrence of recruits, the abundance model gives an approximation of the absolute abundance. In the first situation, when $Y_{i j}$ represents the occurrence (1 being yes; 0 being no) of hake recruits for each haul at location $i$ in year $j$, then it can be modeled as:

$$
\begin{aligned}
& Y_{i j} \sim \operatorname{Ber}\left(\pi_{i j}\right), \quad i=1, \ldots, n_{j i} j=1, \ldots, q \\
& \operatorname{logit}\left(\pi_{i j}\right)=\boldsymbol{X}_{i} \beta+u_{i j} \\
& \beta_{k} \sim N\left(\mu_{\beta_{k^{\prime}}} \rho_{\beta_{k}}\right)
\end{aligned}
$$

where $\pi_{i j}$ is the probability of hake presence at location $i$ in year $j_{i} \boldsymbol{X}_{i} \beta$ represents the fixed effects of the linear predictor whose hyperparameters $\mu_{\beta_{k}}$ and $\rho_{\beta_{k}}$ represent the mean and the precision, respectively; $u_{i j}$ represents different spatio-temporal structures of random effects; the relationship between $\pi_{i j}$ and the covariates of interest and both random effects is the usual logit link; Ber is Bernoulli and $N$ is normal or Gaussian distribution. Specifically, we propose 2 different spatio-temporal structures, the first one consisting of decomposing $u_{i j}$ as:

$$
\begin{aligned}
u_{i j} & =W_{i j}+v_{j} \\
\boldsymbol{W} & \sim N\left(0, Q\left(k_{1} \tau\right)\right) \\
2 \log k & \sim N\left(\mu_{k^{\prime}} \rho_{k}\right) \\
\log \tau & \sim N\left(\mu_{\tau \prime} \rho_{\tau}\right) \\
v_{j} & \sim N\left(0, \rho_{v}\right)
\end{aligned}
$$

where $\boldsymbol{w}=\left(w_{11}, \ldots, w_{n_{q} q}\right)$ represents a unique spatial random effect with parameters $k$ and $\tau$, which are linked to the range and the total variance of the effect (see Lindgren et al. 2011). The structure matrix $Q$ is computed internally by the SPDE approach and represents the GMRF approximation to the continuous GF. $v_{j}$ represents an independent random effect which has been included to allow possible differences between years. The different $\mu$ and $\rho$ hyperparameters represent the corresponding mean and precision of the different prior Gaussian distributions, respectively.
The second spatio-temporal structure is based on decomposing $u_{i j}$ as:

$$
\begin{aligned}
u_{i j} & =W_{i j} \\
\boldsymbol{w}_{j} & \sim N(0, Q(k, \tau)) \\
2 \log k & \sim N\left(\mu_{k}, \rho_{k}\right) \\
\log \tau & \sim N\left(\mu_{\tau}, \rho_{\tau}\right)
\end{aligned}
$$

where $\boldsymbol{w}_{j}=\left(w_{1 j}, \ldots, w_{n_{j}}\right)$ now represents a spatial random effect for each specific year $j$, and the remaining parameters are similar to those in Eq. (2). Note that $\boldsymbol{w}_{j}$ are different realizations of the same model, with the same parameters $k$ and $\tau$.

This latter decomposition is more flexible in the sense that it makes it possible to capture different structures of occurrence for each year. In fact, it would be a good description of those situations in which high abundance or high occurrence probability areas are in different zones every year (that is, they change over time). For those cases in which high presence areas persist over time, Eq. (2) would be the best description.

Once we had a description about the presence areas, our interest was to study the absolute abundance of recruits in those places where the species was present. Note that this is a particularly suitable approach for dealing with high numbers of real zero observations (Martin et al. 2005), because the model deals with (and consequently predicts) the recruit abundance and the occurrence of recruits separately (see Quiroz et al. 2014 for an application in fisheries).

In particular, to study the abundance of recruits, we used a hierarchical Bayesian spatio-temporal modelling similar to that in Eq. (1). Continuous species abundance indices, such as CPUEs, have typically been modelled using lognormal or gamma distributions (Lande et al. 2003, Maunder \& Punt 2004). In our case the lognormal distribution was dismissed because it resulted in a linear negative relationship between the log-CPUEs and the bathymetry, which contradicts hake ecology (OrsiRelini et al. 1989, Recasens et al. 1998, Maynou et al. 2003). Therefore, we modelled the raw CPUE values $Z_{i j}$ observed at location $i$ and year $j$ via the following Gamma model:

$$
\begin{aligned}
& Z_{i j} \sim \operatorname{Ga}\left(a_{i j}, b_{i j}\right), \quad i=1, \ldots, p_{i} j=1, \ldots, q \\
& \log \left(\mu_{i j}\right)=X_{i} \beta+u_{i j} \\
& \beta_{k} \sim N\left(\mu_{\beta_{k^{\prime}}} \rho_{\beta_{k}}\right)
\end{aligned}
$$

where $\mu_{i j}=a_{i j} / b_{i j}, \boldsymbol{X}_{i} \beta$ represents the linear predictor and $u_{i j}$ represents different spatio-temporal structures of random effects. We propose the same decompositions in Eqs. (2) \& (3) for $u_{i j}$. Nevertheless, it must be taken into account that although models in Eqs. (1) \& (4) share most of the notation, the parameters involved are different. 
Following Bayesian reasoning, the parameters are treated as random variables, and prior knowledge is incorporated via prior distributions. In order to express our lack of a priori information about the parameters, we adopted an objective Bayesian approach, an attempt to unify frequentist and Bayesian statistics (Bayarri \& Berger 2004). This approach can be very useful in scenarios where choosing a prior for the parameters is difficult or even infeasible. In our case, we adopted the default vague prior distributions in INLA, and performed visual validation by subsequently verifying that the posterior distributions concentrated well within the support of the priors. Nevertheless, a greater effort should be made to introduce available prior information in the inferential process. All the information from past experiments and observations, performed by ourselves or by others, is of great value, and it is our task to make the best possible use of this information (MartínezAbraín et al. 2014). Posterior distributions of the parameters are the final result of this process. Of particular interest are the posterior mean and standard deviation of the spatial component, which can be used to detect hidden spatial patterns.

A model selection approach was used to select among the different structures in both modellings. Specifically, the Deviance Information Criterion (DIC) (Spiegelhalter et al. 2002) was used as a measure for goodness-of-fit, while the Log-Conditional Predictive Ordinates (LCPO) (Roos \& Held 2011) measures the predictive quality of the models. The smaller the DIC and LCPO values, the better the compromise between fit, parsimony and predictive quality.

\section{Bayesian kriging}

Kriging is the most common prediction technique applied in geostatistics. A widespread method for making a prediction applying Bayesian kriging is to take observations and construct a regular lattice over them. Alternatively, the INLA SPDE module includes a more flexible approach to covering the study area, based on Delaunay triangulations (Lindgren et al. 2011). As opposed to a regular grid, a triangulation is a partition of the region into triangles, satisfying a number of pre-selected constraints that condition the size, shape and density of the triangles in order to ensure smooth transitions between large and small ones. One additional benefit of the SPDE approach is that it provides the posterior conditional distribution for all the nodes in a mesh covering the whole region. It is then possible to obtain an immediate prediction for the latent model, or the response variable at any location in the area, simply by considering the unobserved nodes as missing data.

As a result of this process, we obtained a predictive posterior distribution of recruit occurrence and density for each node in the triangulation (see Lindgren et al. 2011 for a more detailed description of the method, and Muñoz et al. 2013 for its application to fisheries). Once the prediction was performed in the vertices of the triangulation, we linearly interpolated the results to the whole area using the 'inla.mesh. projector' and 'levelplot' functions (see www.r-inla. org and manuals for further details).

\section{RESULTS}

\section{Model selection}

All models obtained by combining environmental variables with the different decompositions of the spatio-temporal structure (Eqs. 2 \& 3) were fitted and compared. All models including the quadratic term for bathymetry had better DIC and LCPO values than those including only a linear relationship. Similarly, the different combinations of models including chl a and sea surface temperature variables had higher DIC and LCPO scores (data not shown). The type of substratum was discarded from the model because estimates of all level categories were centred on zero and had very high standard deviations.

Table 1 shows the goodness-of-fit and predictive quality measures for the Occurrence and Abundance

Table 1. Model comparison for occurrence and abundance of Merluccius merluccius recruits in the western Mediterranean. Deviance Information Criterion (DIC) scores measure goodness-of-fit and Log-Conditional Predictive Ordinates (LCPO) measure the predictive behavior of the model.

In both cases, smaller scores represent better models

\begin{tabular}{|lcc|}
\hline Model & DIC & LCPO \\
\hline Occurrence & 638.38 & 0.31 \\
$\begin{array}{l}\text { Only depth } \\
\text { Common spatial effect only }\end{array}$ & 618.42 & 0.40 \\
$\begin{array}{l}\text { Depth + common spatial effect }+ \\
\quad \text { random noise effect for year }\end{array}$ & 493.89 & 0.23 \\
$\begin{array}{l}\text { Depth + yearly spatial effect } \\
\text { Abundance }\end{array}$ & 627.07 & 0.30 \\
$\begin{array}{l}\text { Only depth } \\
\text { Common spatial effect only }\end{array}$ & 1849.26 & 1.23 \\
$\begin{array}{l}\text { Depth + common spatial effect }+ \\
\text { random noise effect for year }\end{array}$ & 1473.87 & 1.21 \\
Depth + yearly spatial effect & 1491.67 & 1.02 \\
\hline
\end{tabular}



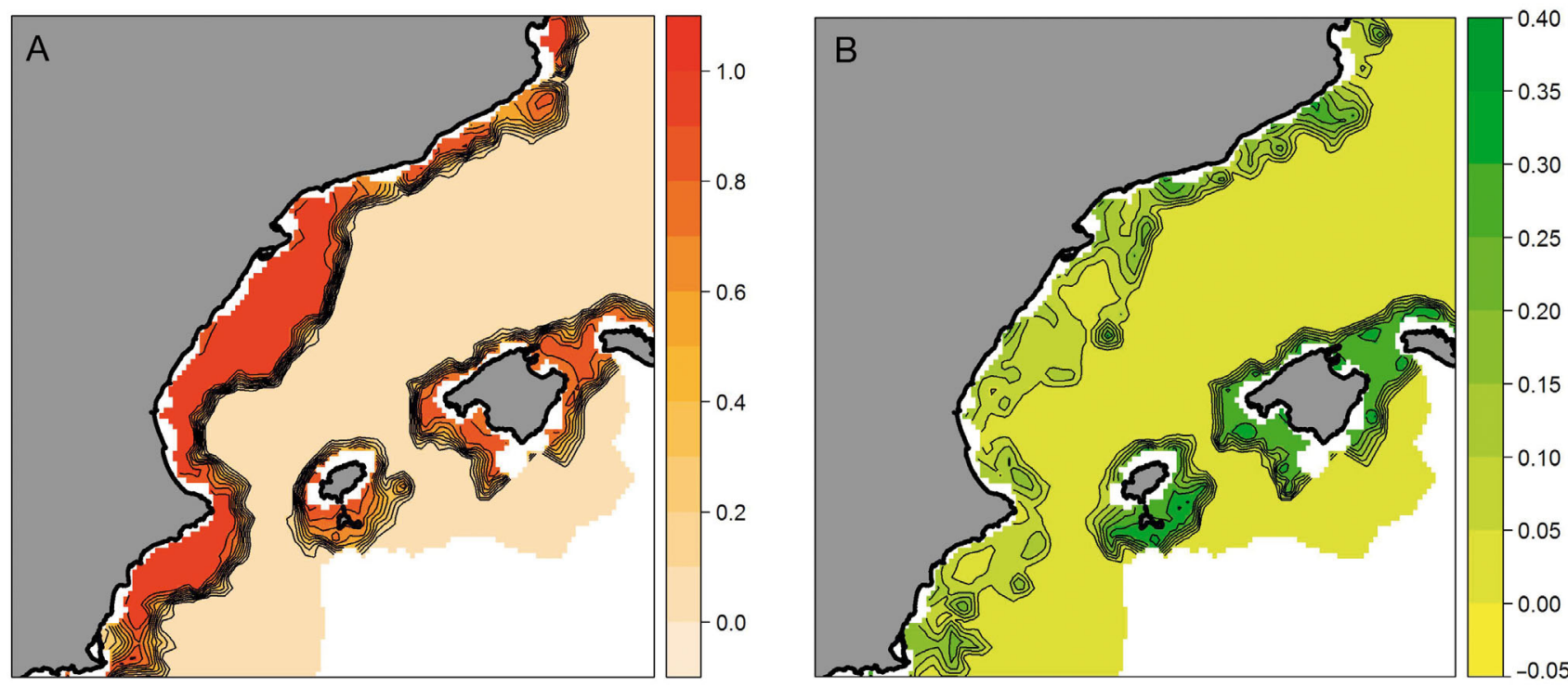

Fig. 2. (A) Spatio-temporal occurrence model output for Merluccius merluccius recruits in the western Mediterranean showing average posterior mean estimates of the probability of presence. (B) Standard deviation during the study time window. Pale contours correspond to low values; dark contours indicate high probability estimates and standard deviations

models. Following the principle of parsimony, the selected models for both occurrence and abundance were the models with the spatio-temporal decomposition in Eq. (2), which share a common spatial effect for all observations and a random noise effect for year in addition to the bathymetric effect. In other words, the selected models are those suggesting persistence of the spatial pattern.

\section{Hake recruit occurrence}

The selected model for the occurrence of recruits revealed the highest probability of presence along the continental shelf and the upper slope (Fig. 2). Accordingly, hake recruitment showed an occurrence peak at between 40 and $180 \mathrm{~m}$ depth (Fig. 3). However, the model also identified some low probability patterns along the continental shelf, especially off the Mar Menor, in the waters off Barcelona and the Palamós Canyon.

It is worth noting the importance of the spatial effect in the peak occurrence estimates. This effect identified the spatial pattern of recruitment at similar depths throughout the study area. In those areas where the spatial effect was high, the probability of occurrence also tended to be high and vice versa (Figs. 2 \& 4). For instance, the spatial effect around the Balearic Islands (Fig. 4A) was almost negligible (we had no observations there) and the predicted probability map (Fig. 2A) is thus extremely smooth, very close to the estimate provided by the environmental covariate alone. With regard to the scale of the temporal unstructured term, its variance was around 3 orders of magnitude below that of the spatial random effect (see the $x$-axes in Fig. 5).

\section{Hake recruit abundance}

In the second situation, the highest abundance areas were also located along the continental shelf

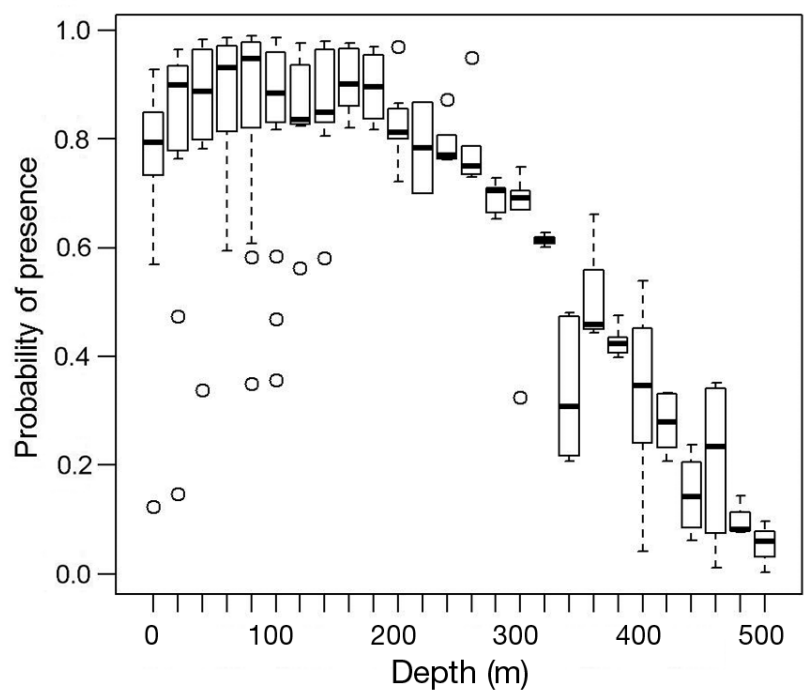

Fig. 3. Mean of the fitted values at the prediction nodes of the occurrence model. Each boxplot corresponds to a $20 \mathrm{~m}$ interval 

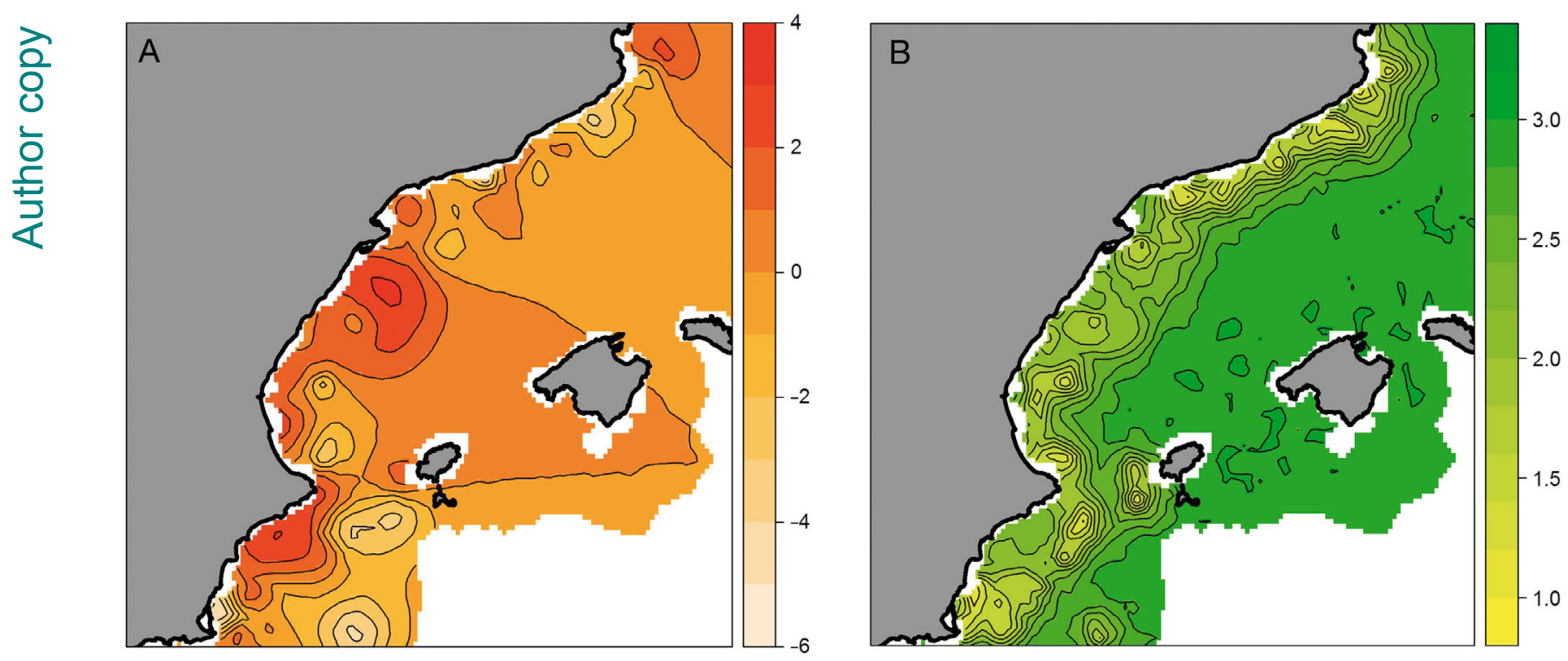

Fig. 4. (A) Posterior mean of the spatial effect in the occurrence model; and (B) standard deviation. Pale contours correspond to low values; dark contours indicate high increments in the linear predictor and high standard deviations

and upper slope (Fig. 6), coinciding with the estimated effect of the bathymetry. The bathymetric peak abundance was around the 80 to $180 \mathrm{~m}$ strata derived from the predicted abundance estimates (Fig. 7). However, these abundance hotspots were much more localised than the occurrence (as expected). In fact, the sizes of these areas were around $10 \mathrm{~km}$ in diameter.

It is again important to note the influence of the spatial effect on the localisation of the persistent high density areas (see Figs. 6 \& 8). The importance of the spatial term was again very clear around the Balearic Islands compared to the continental area. Around the islands we had an almost negligible spatial effect due to a lack of observations, and the estimates were

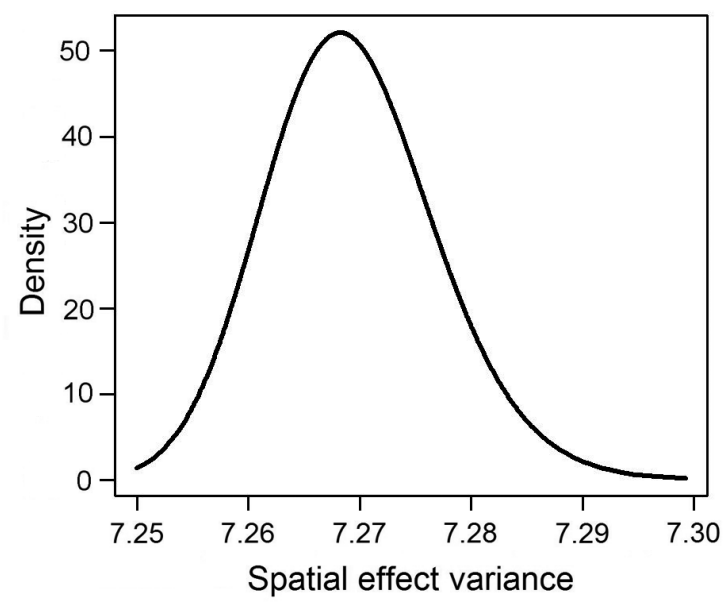

basically determined by the bathymetry. This resulted in a very smooth spatial pattern (Fig. 8A), in contrast to the continental zone. The scale of the variance of the fitted random noise effect for year was smaller than that of the spatial random effect (see the $x$-axes in Fig. 9).

\section{Nursery grounds}

At least 3 high abundance and occurrence areas were identified. A small hotspot was located a few kilometers off the city of Valencia, while the highest abundance hotspot was located some kilometers to the northeast, around the Columbretes Islands. This

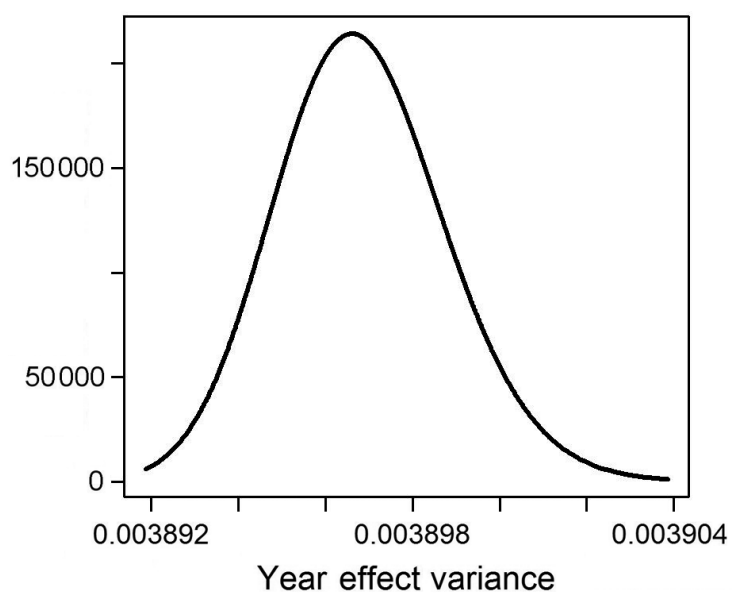

Fig. 5. Estimated distribution of the variance for the spatial effect (left) and independent random effect for year (right) in the occurrence model. Note the different scale in which the variance is measured 

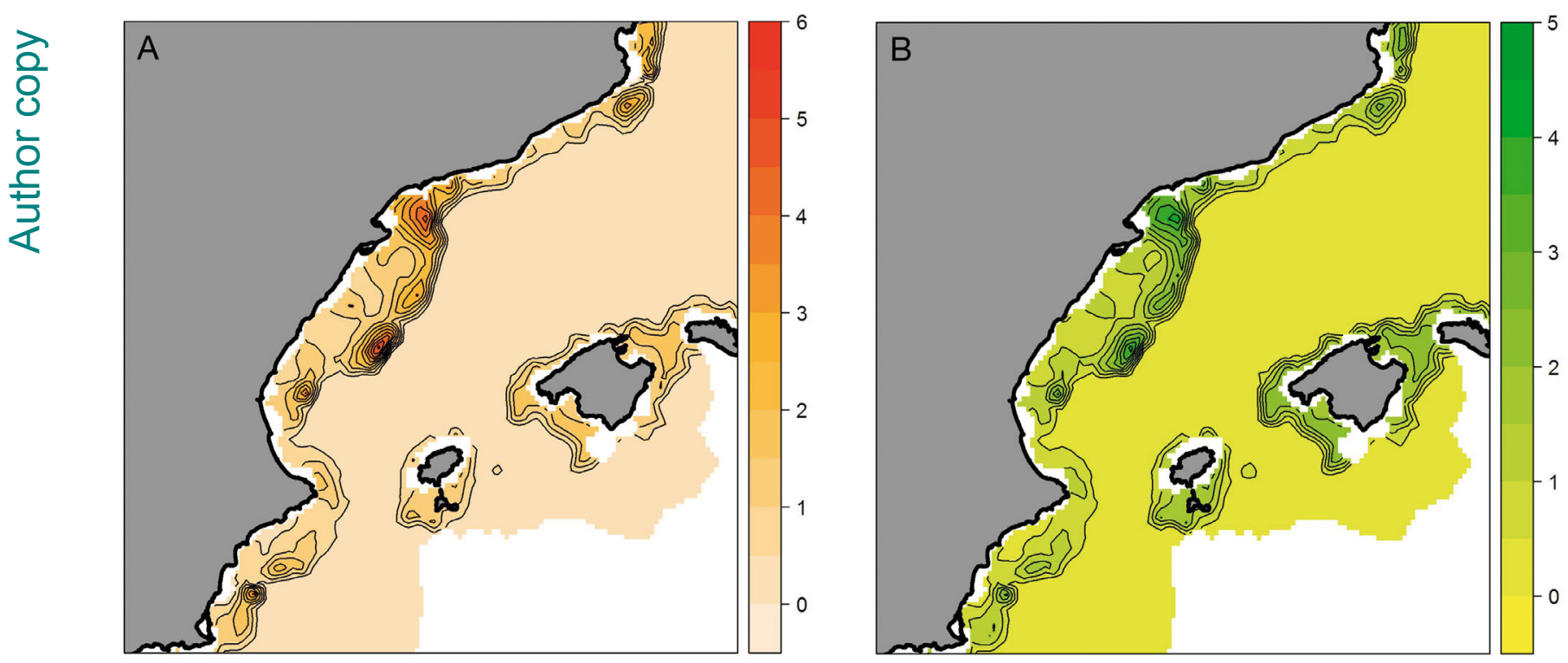

Fig. 6. (A) Spatio-temporal abundance model output for Merluccius merluccius recruits in the western Mediterranean showing average posterior mean abundance estimates in $\mathrm{kg}$ per 30 min tow using MEDIterranean Trawl Survey (MEDITS) gear; and (B) standard deviation during the study time window. Pale contours correspond to low values; dark contours indicate high abundance estimates and standard deviations

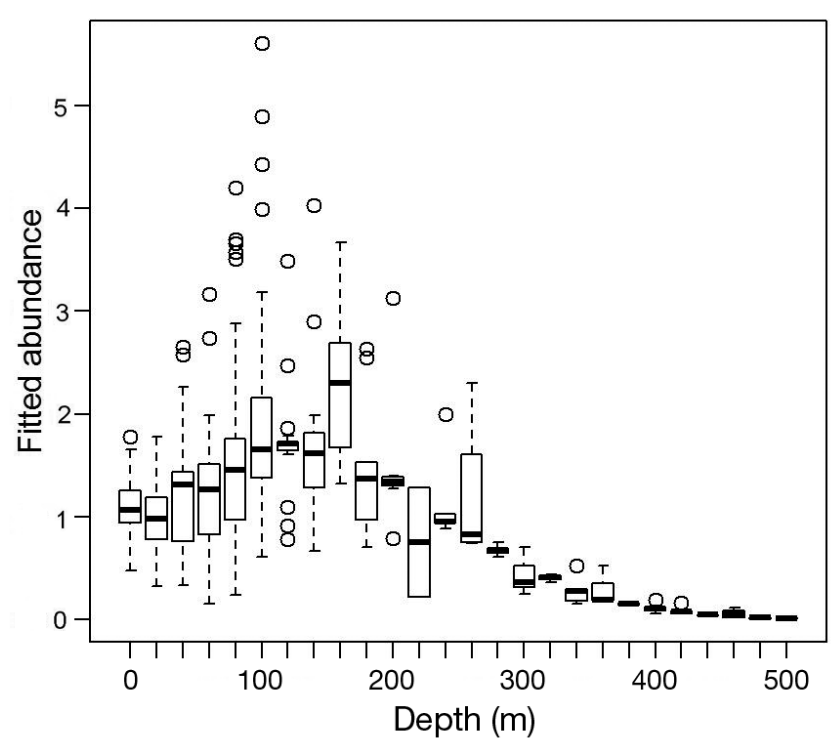

Fig. 7. Mean of the fitted values at the prediction nodes of the abundance model. Each boxplot corresponds to a $20 \mathrm{~m}$ interval

hotspot extended transversally to the bathymetric slope and connected through a moderate density region to another high density area north of the Ebro delta. These 2 highest abundance hotspots encompass around $650 \mathrm{~km}^{2}$ of the total $18000 \mathrm{~km}^{2}$ area of the 50 to $200 \mathrm{~m}$ depth strata in the GSA 06. The areas close to the Palamós Canyon and Mar Menor showed relatively high abundance estimates, while the esti- mated occurrences were not that high. This behavior suggests that the aggregation patterns are diffuse, and hence these areas were not considered to be important nursery grounds.

\section{DISCUSSION}

The implementation of an EAFM requires the spatial characterisation of key life cycle habitats of exploited stocks (Crowder \& Norse 2008, FAO 2008). In this respect, the identification of nursery grounds has attracted special interest among researchers because of the impact that unselective gear could have on this critical phase. Here, we propose a methodological approach for the identification of fish nurseries based on the spatio-temporal persistence of hotspots. This may be particularly helpful in the absence of quantitative data on the contribution of nursery habitats to the adult population (Colloca et al. 2009).

The proposed methodology assesses the persistence of a spatial process by comparing 2 spatio-temporal structures, while density hotspots are identified by combining occurrence and abundance information (Maravelias 1999). Consequently, compared to the methodology proposed by Colloca et al. (2009), this approach not only reduces the number of steps needed to assess the persistence of the spatial process but also includes information on absence observations through the occurrence model, so as to better 

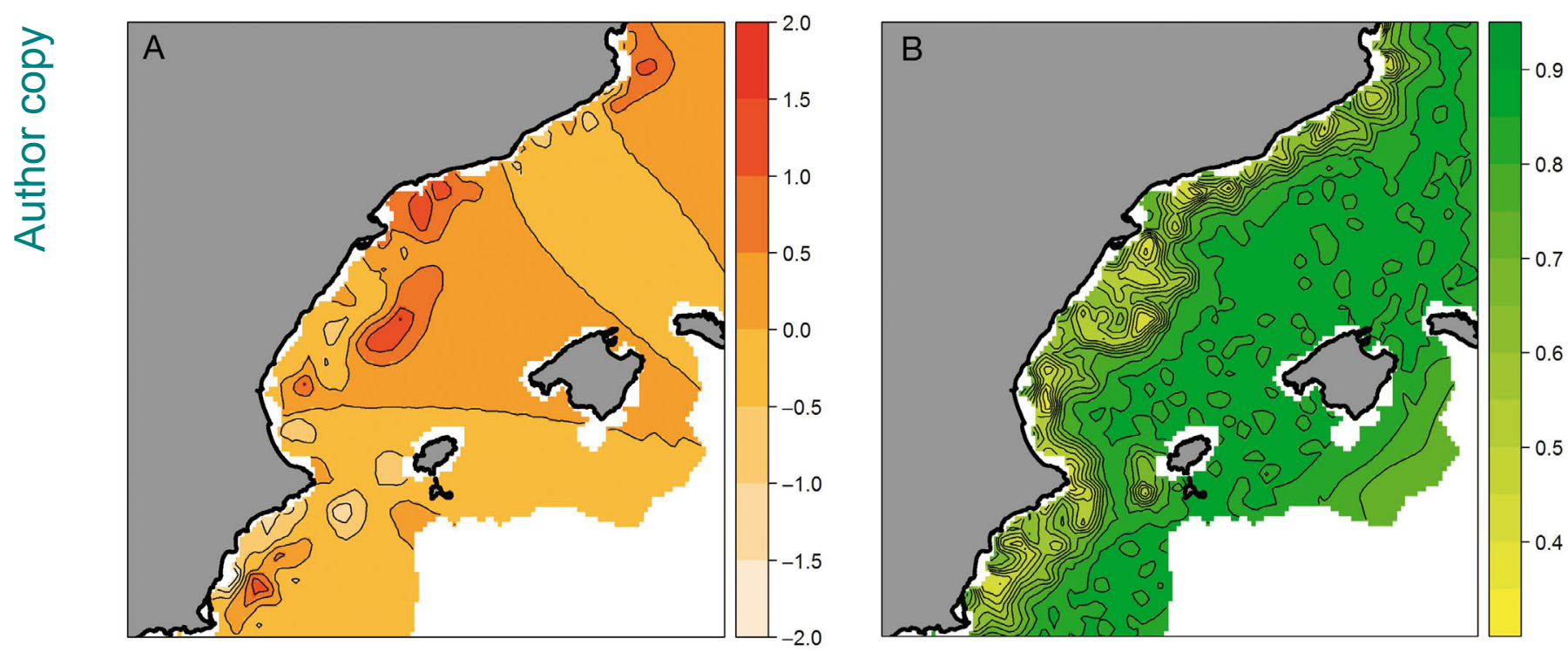

Fig. 8. (A) Posterior mean and (B) standard deviation of the spatial effect in the abundance model. Pale contours correspond to low values; dark contours indicate high increments in the linear predictor and high standard deviations

characterise the spatial presence of hake recruits. In fact, areas where high abundance estimates concur with low occurrence estimates have not been highlighted as important nursery grounds. This method, however, may not be applicable to those cases where the spatial structure is not persistent. In such cases, the methodology proposed by Colloca et al. (2009), using geostatistical aggregation curves, could better assess the importance of these areas.

Our results suggest that the distribution of hake recruits in the western Mediterranean Sea is persistent over the years, helping us to identify at least 3 nursery grounds. The waters surrounding the Columbretes Islands show both high abundance and occurrence estimates. These islands have been a Marine Protected Area since 1989, and thus provide a stable, high quality ecosystem to stocks that could be exporting hake adults and recruits to adjacent areas, as has been reported with other species (Stobart et al. 2009). A meso-scale study of the effect of the Columbretes MPA on the hake population could confirm this hypothesis. Another nursery ground is located north of the Ebro delta. High run-off areas like this are well known for boosting primary production, and consequently larvae survival rate (Sutcliffe 1973, Thórdardóttir 1986); thus, protecting this sort of environment could be especially beneficial to the first stages of recruits (Nagelkerken et al. 2013).
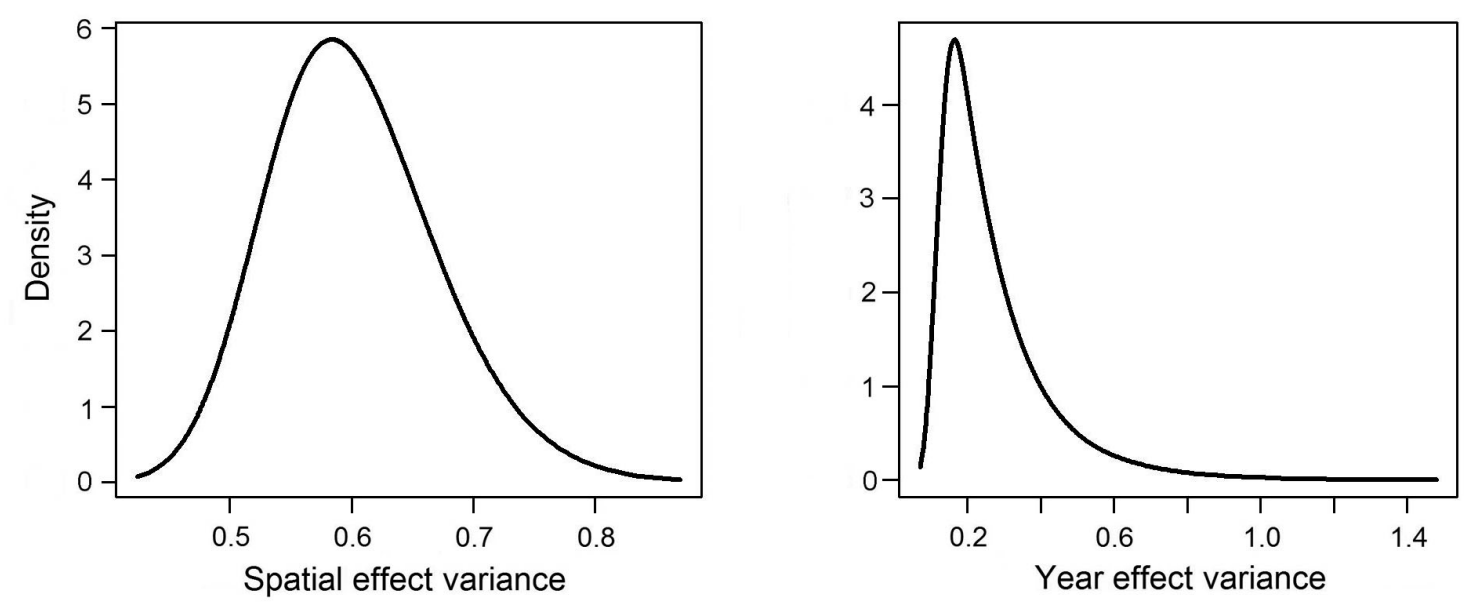

Fig. 9. Estimated distribution of the variance for the spatial effect (left) and independent random effect for year (right) in the abundance model 
Complementary studies (e.g. setting a smaller cut-off length) could assess the importance of these areas for those early stages using a similar methodology. A third smaller nursery area is estimated to be a few kilometers off Valencia. This hotspot has smaller total abundance estimates than the other 2, probably as a consequence of high fishing pressure originating from the fishing fleets based at Valencia and nearby ports. Fishing effort data could confirm such a hypothesis.

The effect of bathymetry on the distribution of hake recruits is well known, and accordingly, we determined peak abundance to occur at approximately the 80 to $180 \mathrm{~m}$ depth strata. Similar results have been reported by other authors in other areas of the Mediterranean (Orsi-Relini et al. 1989, Recasens et al. 1998, Maynou et al. 2003). However, the estimated effect of bathymetry in this study shows slightly different optimum values for abundance and for occurrence, likely because each model omits part of the data. The remaining variables included in the analysis (i.e. the type of substratum, sea surface temperature and chl a concentration) added no relevant information to the distribution of hake recruits.

The relatively small size of the identified peak abundance areas of hake recruits compares favorably with the results of Colloca et al. (2009) and Garofalo et al. (2011). The relatively small distances between them may also suggest the implementation of a network of interconnected reserves (Roberts et al. 2003) for an effective marine spatial planning (MSP) in the western Mediterranean Sea. Moreover, the small size of the hotspots could be a key feature that eases communication with the fisheries sector in the implementation of EAFM directives, since it would presumably have a relatively small impact on fishermen. Indeed, such an impact could be assessed using fishing effort information to minimize impact versus protection. An effective MSP should include the spatio-temporal dynamism of species over the full year (Crowder \& Norse 2008); however, the MEDITS survey used in this study covered only a short period of time from late spring to early summer in this area. Consequently, the fitted models can only reflect a snapshot view of the expected relationships and distribution. Hake reproduce actively throughout the year in the Mediterranean (Recasens et al. 1998, 2008), so future studies should investigate their spatial distribution during the remaining months of the year, and include other sources of information such as fishery-dependent data in order to complete this framework. If such studies suggest a persistent pattern over the full year, the planning of permanent hake nursery fisheries restricted areas (FRAs) could be suggested. Otherwise, more flexible spatial planning would be needed.

Results such as these, expanded to incorporate multiple species and life stages, and combined with information on the distribution of fishing activity could be a good approach to implementing an effective ecosystem-based MSP that embraces the EAFM requirements. In this respect, the INLA package for $\mathrm{R}$ (Rue et al. 2013) might be a key geostatistical tool due to its notable flexibility in fitting complex models (Illian et al. 2012, Blangiardo et al. 2013) and its computational efficiency (Beguin et al. 2012).

Acknowledgements. D.C., A.L.Q. and F.M. thank the Ministerio de Educación y Ciencia (Spain) for financial support (jointly financed by the European Regional Development Fund) via Research Grants MTM2010-19528 and MTM 2013-42323-P. The authors express their gratitude to all the people that work in the MEDITS surveys. The authors also very much appreciate the suggestions and comments made by 3 anonymous reviewers on the original manuscript, which greatly improved the final version.

\section{LITERATURE CITED}

Abella A, Fiorentino F, Mannini A, Relini LO (2008) Exploring relationships between recruitment of European hake (Merluccius merluccius L. 1758) and environmental factors in the Ligurian Sea and the Strait of Sicily (Central Mediterranean). J Mar Syst 71:279-293

Acker JG, Leptoukh G (2007) Online analysis enhances use of NASA Earth science data. Eos Trans Am Geophys Union 88:14-17

Banerjee S, Gelfand AE, Carlin BP (2003) Hierarchical modeling and analysis for spatial data. CRC Press, Boca Raton, FL

Bartolino V, Ottavi A, Colloca F, Ardizzone GD, Stefánsson G (2008) Bathymetric preferences of juvenile European hake (Merluccius merluccius). ICES J Mar Sci 65: 963-969

Bayarri MJ, Berger JO (2004) The interplay between Bayesian and frequentist analysis. Stat Sci 19:58-80

Beck MW, Heck KL Jr, Able KW, Childers DL and others (2001) The identification, conservation, and management of estuarine and marine nurseries for fish and invertebrates: a better understanding of the habitats that serve as nurseries for marine species and the factors that create site-specific variability in nursery quality will improve conservation and management of these areas. Bioscience 51:633-641

Beguin J, Martino S, Rue H, Cumming SG (2012) Hierarchical analysis of spatially autocorrelated ecological data using integrated nested Laplace approximation. Methods Ecol Evol 3:921-929

Bellido JM, Quetglas AC, Rodriguez MG, Jimenez TG, Aguilar MG (2014) The obligation to land all catches: consequences for the Mediterranean. Policy Department B: Structural and Cohesion Policies, European Parliament Directorate-General for Internal Policies, Brussels Bertrand JA, Gil De Sola L, Papaconstantinou C, Relini G, 
Souplet A (2002) The general specifications of the MEDITS surveys. Sci Mar 66:9-17

Blangiardo M, Cameletti M, Baio G, Rue H (2013) Spatial and spatio-temporal models with R-INLA. Spat Spatiotemporal Epidemiol 7:39-55

Caddy J (2000) A fisheries management perspective on marine protected areas in the Mediterranean. Environ Conserv 27:98-103

> Colloca F, Bartolino V, Lasinio GJ, Maiorano L, Sartor P, Ardizzone G (2009) Identifying fish nurseries using density and persistence measures. Mar Ecol Prog Ser 381: 287-296

Cressie NAC (1993) Statistics for spatial data. John Wiley \& Sons, Hoboken, NJ

Crowder L, Norse E (2008) Essential ecological insights for marine ecosystem-based management and marine spatial planning. Mar Policy 32:772-778

Dahlgren CP, Kellison GT, Adams AJ, Gillanders BM and others (2006) Marine nurseries and effective juvenile habitats: concepts and applications. Mar Ecol Prog Ser 312:291-295

Diggle PJ, Ribeiro PJ (2007) Model-based geostatistics. Springer, New York, NY

> Druon J, Fiorentino F, Murenu M, Knittweis L and others (2015) Modelling of European hake nurseries in the Mediterranean Sea: an ecological niche approach. Prog Oceanogr 130:188-204

FAO (2008) The ecosystem approach to fisheries. Technical guidelines for responsible fisheries. Fisheries and Aquaculture Department, FAO, Rome

> Garofalo G, Fortibuoni T, Gristina M, Sinopoli M, Fiorentino F (2011) Persistence and co-occurrence of demersal nurseries in the Strait of Sicily (central Mediterranean): implications for fishery management. J Sea Res 66:29-38

Gelfand A, Silander J, Wu S, Latimer A, Lewis P, Rebelo A, Holder M (2006) Explaining species distribution patterns through hierarchical modeling. Bayesian Anal 1:41-92

Gillanders BM, Able KW, Brown JA, Eggleston DB, Sheridan PF (2003) Evidence of connectivity between juvenile and adult habitats for mobile marine fauna: an important component of nurseries. Mar Ecol Prog Ser 247:281-295

Illian J, Ørbye S, Rue H (2012) A toolbox for fitting complex spatial point process models using Integrated Nested Laplace Approximation (INLA). Ann Appl Stat 6: 1499-1530

Lande R, Engen S, Saether BE (2003) Stochastic population dynamics in ecology and conservation. Oxford University Press, Oxford

> Lindgren F, Rue H, Lindström J (2011) An explicit link between Gaussian fields and Gaussian Markov random fields: the stochastic partial differential equation approach. J R Stat Soc B Methods 73:423-498

Lleonart J (2005) Review of the state of the world fishery resources. FAO Fish Tech Pap 457:49-64

Maravelias CD (1999) Habitat selection and clustering of a pelagic fish: effects of topography and bathymetry on species dynamics. Can J Fish Aquat Sci 56:437-450

Martin TG, Wintle BA, Rhodes JR, Kuhnert PM and others (2005) Zero tolerance ecology: improving ecological inference by modelling the source of zero observations. Ecol Lett 8:1235-1246

Martínez-Abraín A, Conesa D, Forte A (2014) Subjectivism as an unavoidable feature of ecological statistics. Anim Biodivers Conserv 37:141-143

Maunder MN, Punt AE (2004) Standardizing catch and effort data: a review of recent approaches. Fish Res 70:
$141-159$

Maynou F, Lleonart J, Cartes JE (2003) Seasonal and spatial variability of hake (Merluccius merluccius L.) recruitment in the NW Mediterranean. Fish Res 60:65-78

> Muñoz F, Pennino MG, Conesa D, López-Quílez A, Bellido J (2013) Estimation and prediction of the spatial occurrence of fish species using Bayesian latent Gaussian models. Stoch Environ Res Risk A 27:1171-1180

Nagelkerken I, Sheaves M, Baker R, Connolly RM (2013) The seascape nursery: a novel spatial approach to identify and manage nurseries for coastal marine fauna. Fish Fish 16:362-371

Orsi-Relini L, Cappanera M, Fiorentino F (1989) Spatialtemporal distribution and growth of Merluccius merluccius recruits in the Ligurian Sea. Cybium 13:263-270

> Pennino MG, Muñoz F, Conesa D, López-Quílez A, Bellido J (2014) Bayesian spatio-temporal discard model in a demersal trawl fishery. J Sea Res 90:44-53

Planque B, Loots C, Petitgas P, Lindström U, Vaz S (2011) Understanding what controls the spatial distribution of fish populations using a multi-model approach. Fish Oceanogr 20:1-17

Quiroz ZC, Prates MO, Rue H (2014) A Bayesian approach to estimate the biomass of anchovies in the coast of Perú. Biometrics 64:1-24

Recasens L, Lombarte A, Morales-Nin B, Torres GJ (1998) Spatiotemporal variations in the population structure of the European hake in the northwestern Mediterranean. J Fish Biol 53:387-401

- Recasens L, Chiericoni V, Belcari P (2008) Spawning pattern and batch fecundity of the European hake (Merluccius merluccius (Linnaeus, 1758)) in the western Mediterranean. Sci Mar 72:721-732

> Roberts CM, Branch G, Bustamante RH, Castilla JC and others (2003) Application of ecological criteria in selecting marine reserves and developing reserve networks. Ecol Appl 13:215-228

> Roos M, Held L (2011) Sensitivity analysis in Bayesian generalized linear mixed models for binary data. Bayesian Anal 6:259-278

Rue H, Held L (2004) Gaussian Markov random fields: theory and applications. CRC Press, Boca Raton, FL

- Rue H, Martino S, Chopin N (2009) Approximate Bayesian inference for latent Gaussian models by using integrated nested Laplace approximations. J R Stat Soc B Methods 71:319-392

Rue H, Martino S, Lindgren F, Simpson D, Riebler A (2013) INLA: functions which allow to perform full Bayesian analysis of latent Gaussian models using Integrated Nested Laplace Approximation. R package version 0.01383402327, www.r-inla.org

> Spiegelhalter DJ, Best NG, Carlin BP, Van Der Linde A (2002) Bayesian measures of model complexity and fit. J R Stat Soc B Methods 64:583-639

Stobart B, Warwick R, González C, Mallol S, Díaz D, Reñones O, Goñi R (2009) Long-term and spillover effects of a marine protected area on an exploited fish community. Mar Ecol Prog Ser 384:47-60

Sutcliffe WH Jr (1973) Correlations between seasonal river discharge and local landings of American lobster (Homarus americanus) and Atlantic halibut in the Gulf of St. Lawrence. J Fish Res Board Can 30:856-859

Thórdardóttir T (1986) Timing and duration of spring blooming south and southwest of Iceland. In: Skreslet S (ed) The role of freshwater outflow in coastal marine ecosystems. Springer-Verlag, Berlin, p 345-360 